\title{
Apontamentos críticos sobre concepções de linguagem na formação superior de docentes indígenas: diálogo intercultural como diálogo interepistêmico
}

\section{Critical notes on conceptions of language in indigenous teachers higher education: intercultural dialogue as an inter-epistemic dialogue}

\author{
André Marques do Nascimento* \\ $U F G$ \\ ${ }^{*}$ Doutor em Letras \\ e Linguística. \\ marquesandre@ \\ yahoo.com.br
}

Resumo: Busco neste trabalho apresentar apontamentos críticos situados nas experiências implementadas na formação superior de docentes indígenas sob perspectiva bilíngue intercultural, através da análise de representações e ideologias subjacentes às categorias e concepções hegemônicas de língua, língua materna e escrita e de sua apropriação por docentes indígenas em contextos de complexidade intercultural. $\mathrm{O}$ argumento principal deste trabalho fundamenta-se na necessidade de que as concepções indígenas sobre linguagem sejam consideradas em nível epistemológico, sob risco de que este modelo educativo perpetue exclusões que historicamente acometem os povos indígenas brasileiros via instituições educativas.

Palavras-chave: Formação Superior Indígena. Concepções de Linguagem. Diálogo Interepistêmico.

\begin{abstract}
This work provides critical notes situated in the experiences implemented in a Indigenous Teachers Higher Education course in a bilingual intercultural perspective through the analysis of representations and ideologies underlying hegemonic categories and conceptions of language, mother tongue, and writing, as well of its appropriation by indigenous teachers in contexts of intercultural complexity. The main argument of this paper is based on the need for indigenous conceptions of language being considered on an epistemological level in order to avoid the risk that this educational model perpetuates exclusions that historically affect Brazilian Indigenous peoples through educational institutions.
\end{abstract}

Keywords: Indigenous Higher Education. Conceptions of Language. Interepistemic dialogue. 


\section{Introdução}

A motivação inicial para as reflexões aqui apresentadas ${ }^{1}$ origina-se no contexto das atividades do curso de Educação Intercultural para formação superior de docentes indígenas da Universidade Federal de Goiás. Como um dos principais objetivos do curso, busca-se a formação indígena a partir de um paradigma de educação emancipatório, descolonizante e concebido a partir das, e intrinsecamente vinculado às, diferentes e particulares dimensões das vidas destes povos e do ideal de relações menos injustas com a sociedade não-indígena, histórica e politicamente instituída como "a sociedade hegemônica". Subjazem aos objetivos gerais do curso as concepções de interculturalidade e de transdisciplinaridade, diversidade e sustentabilidade, implementados como princípios pedagógicos e eixos direcionadores dos diferentes processos e ações pedagógicas desenvolvidos nas atividades de formação docente.

No referido curso, estão presentes atualmente docentes indígenas pertencentes aos povos Apinajé, Canela, Gavião, Guajajara, Guarani, Javaé, Karajá, Karajá Xambioá, Kamaiurá, Krahô, Krikati, Tapirapé, Tapuia, Timbira, Xacriabá, Xavante, Xerente e Waurá, provenientes de diferentes Terras Indígenas, situadas nos estados brasileiros de Goiás, Maranhão, Mato Grosso e Tocantins. Ao considerar esta diversidade sociocultural, bem como a longa trajetória de violências e exclusões de toda ordem impostas aos povos indígenas brasileiros, reconheço a importância e o ineditismo do atual contexto histórico no qual estes diferentes povos se fazem presentes numa 'universidade', contexto que, dadas as concepções pedagógicas mencionadas, pressupõe, ou deveria pressupor, o (re)encontro dialógico crítico e igualitário com ontologias e epistemologias de diferentes matrizes culturais, historicamente apagadas, silenciadas e deslegitimadas por uma geopolítica do poder e, portanto, do conhecimento que estrategicamente alçou uma forma parcial e local de conhecimento à categoria de 'universal'.

A imprescindibilidade da (re)emergência de ontologias e epistemologias indígenas e seu posicionamento em condições dialógicas simétricas em relação aos conhecimentos de matriz não-indígena subjaz às próprias concepções de interculturalidade e transdisciplinaridade, adotadas pelo curso de Educação Intercultural da UFG, tornando-se mesmo condição sine qua non para sua plena implementação, pois, conforme Walsh (2009), a assunção de uma perspectiva epistemológica intercultural é um passo importante para a desestabilização das estruturas de poder excludente. Para a autora, tratar de uma política epistêmica da interculturalidade na educação significa a possibilidade de estender o debate para outros níveis, focalizando o próprio problema da ciência em si, cujas bases fundadas no projeto moderno/colonial instituiu e mantém uma ordem hierárquica racial que privilegia um único ponto de vista. Desta forma, torna-se possível

${ }^{1}$ Este trabalho inserese no âmbito do projeto de pesquisa "Alternativas situadas para descolonização de práticas, ideologias e regimes de linguagem em contextos pós-coloniais interculturais", coordenado pelo autor. 
considerar a construção de novos marcos epistemológicos que pluralizam, problematizam e desafiam a noção de um pensamento e conhecimento totalitários, únicos e universais, partindo de uma política e ética que sempre mantêm como presentes as relações do poder às quais foram submetidos estes conhecimentos. Assim, alenta novos processos, práticas e estratégias de intervenção intelectual que poderiam incluir, entre outras, a revitalização, revalorização e aplicação dos saberes ancestrais, não como algo ligado a uma localidade e temporalidade do passado, mas como conhecimentos que têm contemporaneidade para criticamente ler o mundo, e para compreender, (re)aprender e atuar no presente (WALSH, 2009, p. 24-25).

Em outras palavras, e aqui se coloca a principal justificativa das problematizações a serem apresentadas, não há como se pensar em projetos que visem à implementação de dimensões epistemológicas interculturais transdisciplinares, sem que se abram vias para o conhecimento, para a compreensão e, só então, para a valorização de lógicas culturalmente distintas ou para "sistemas de saberes plurais" como os dos povos indígenas brasileiros, que desafiem e desestabilizem as bases sobre as quais se fundam o pensamento e o conhecimento totalitários e alegadamente 'universais’ do sistema mundo moderno/colonial eurocentrado e historicamente hegemônico e, o que é mais importante, que contribuam com o propósito mais amplo de proporcionar novas perspectivas a partir das quais se possa “criticamente ler o mundo, e para compreender, (re)aprender e atuar no presente”. Caso contrário, projetos que se propõem interculturais correm o sério risco de perpetuarem a hierarquização ontológica e epistemológica, bases fundamentais da construção da hegemonia eurocêntrica às quais estiveram sujeitos os povos indígenas brasileiros desde o início do confronto colonial.

Como professor da área de estudos da linguagem, algumas experiências vivenciadas em diferentes contextos pedagógicos no âmbito do curso de Educação Intercultural da UFG me impuseram questionamentos concernentes aos limites e à pertinência da parcialidade hegemônica das bases teórico-conceptuais a partir das quais desenvolvo minhas atividades docentes e de pesquisa, oriundas, principalmente, da Linguística e da Linguística Aplicada de matriz anglo-eurocêntrica, ao mesmo tempo em que me proporcionaram insights significativos quanto a outras possibilidades de compreensão de fenômenos relativos à linguagem situados em contextos interculturais pós-coloniais. Estas experiências suscitaram algumas problematizações concernentes, por exemplo, à categoria língua empregada e bastante naturalizada nos estudos da linguagem, assim como as correlatas como língua materna, entre outras, como escrita etc.

No que se segue, busco apresentar algumas situações geradoras das reflexões aqui apresentadas, interpretando-as desde perspectivas teórico-analíticas críticas. Muito embora não apresente aqui postulações definitivas quanto aos problemas apontados, acredito que as perspectivas 
interpretativas aqui adotadas sirvam como base para reflexões mais aprofundadas sobre as situações mencionadas, assim como a outras que, inevitavelmente, ocorrem em zonas de contato intercultural, aqui compreendidas como "os espaços sociais onde as culturas se encontram, se chocam e se enfrentam, normalmente em contextos de relações de poder altamente assimétricas” (PRATT, 1991, p. 34).

\section{Perspectivas teóricas}

As reflexões aqui apresentadas partem do pressuposto de que os problemas concernentes às formas de (inter)compreensão contemporâneas sobre a linguagem em contextos interculturais não podem ser compreendidos e enfrentados no campo da educação intercultural se não forem localizados num enquadre interpretativo coerente e mais amplo. Assim, uma das assunções deste trabalho situa as origens destes problemas no fato histórico do colonialismo iniciado com a conquista do território e dos povos nativos latino-americanos, levado a cabo pelas potências europeias, especialmente entre os séculos XVI a XVIII, como também na colonialidade, ou seja, em seus impactos e desdobramentos que se fazem sentir, desde então e até a atualidade, em diferentes dimensões das relações pós-coloniais interculturais, principalmente, entre indígenas e não-indígenas.

Conforme Quijano (1992, p. 437)², por colonialismo pode-se compreender, de maneira geral, "a relação de dominação direta, política, social e cultural dos europeus sobre os conquistados de todos os continentes", pautada principalmente na classificação hierárquica de todas as populações dominadas, através de mecanismos pelos quais "os sujeitos submetidos à descrição e à classificação do enunciado não participam na classificação de que são objetos” (MIGNOLO, 2010, p. 72). Neste processo, inicia-se não apenas uma completa reorganização colonial do mundo política e economicamente, como também a constituição de uma ordem hierárquica racial, assim como de saberes, línguas, memórias e imaginários, cujo padrão se torna a experiência europeia (LANDER, 2000, p. 14-15). Nesta direção, complementa Quijano (2000, p. 202), os colonizadores reprimiram como puderam as formas de produção de conhecimento dos povos colonizados, seus padrões de produção de sentidos, seu universo simbólico, seus padrões de expressão e de objetivação da subjetividade, de maneira mais profunda, violenta e duradoura entre os povos indígenas da 'América Ibérica' e, de maneira semelhante, na África. Além disso, continua o autor, todo este violento processo implicou "uma colonização das perspectivas cognitivas, dos modos de produzir ou outorgar sentido aos resultados da experiência material ou intersubjetiva, do imaginário, do universo de relações intersubjetivas do mundo, em síntese, da cultura” (QUIJANO, 2000, p. 202), nela incluídas suas práticas comunicativas.
${ }^{2}$ Todas as traduções de citações diretas e indiretas neste trabalho são de minha responsabilidade. 
A ideia de colonialidade, por sua vez, visa, como categoria analítica, a compreender os impactos e os desdobramentos do colonialismo ao buscar desvelar não apenas as estratégias de controle e dominação coloniais diretas, mas a continuidade de uma estrutura que mantém a situação de dominação, cujas origens se situam na relação colonial. Maldonado-Torres (2007, p. 131), sob a mesma perspectiva, concebe a colonialidade como o resultado do colonialismo moderno que não se limita à relação formal de poder entre conquistados e conquistadores, englobando também a “forma como o trabalho, o conhecimento, a autoridade e as relações intersubjetivas se articulam entre si através do mercado capitalista mundial e da ideia de raça” e como esta "se mantém viva nos manuais de aprendizagem, no critério para o bom trabalho acadêmico, na cultura, no sentido comum, na autoimagem dos povos, nas aspirações dos sujeitos e em muitos outros aspectos de nossa experiência moderna”. Em outras palavras, não há como se pensar a modernidade eurocentrada, sem sua contraparte ocultada, a colonialidade (MIGNOLO, 2011).

Ecoando e interpretando a proposta de colonialidade como categoria de análise de situações pós-coloniais interculturais latino-americana em diferentes e complexas dimensões, Mignolo (2010, p. 13-14) a analisa em duas direções simultâneas, uma analítica e outra programática. Em sua dimensão analítica, o conceito de colonialidade se abre para a reconstrução e para a restituição de histórias silenciadas, subjetividades reprimidas, linguagens e conhecimentos subalternizados pela ideia de totalidade, definida sob o nome de modernidade e racionalidade. Em sua dimensão programática, assume o caráter de ‘desprendimento’ epistêmico no âmbito social. Neste sentido, conforme Mignolo (2010), o desprendimento requer um giro epistêmico decolonial, cuja genealogia se funda nos conhecimentos adquiridos desde outras epistemologias, outros princípios de conhecer, outras economias, outras políticas e outras éticas. Assim, “a 'comunicação intercultural’ deve ser interpretada como comunicação inter-epistêmica [...]. A noção de desprendimento direciona o giro decolonial até uma universalidade-outra, ou seja, em direção a uma pluriversalidade como projeto universal” (MIGNOLO, 2010, p. 17, destaques no original). Nesta direção, o projeto de decolonialidade epistêmica envolve, necessariamente, “o incontrolável terreno da desnaturalização terminológica. Isto implica que uma estratégia de desprendimento consiste em desnaturalizar os conceitos e os campos conceptuais que totalizam uma realidade” (MIGNOLO, 2010, p. 38-39).

Para os propósitos deste trabalho, interessa compreender como também as categorias referentes a linguagem são parte de um projeto moderno/ colonial e como se tornaram naturalizadas no mundo ocidental, como a própria ideia de 'língua', desde o ponto de vista hegemônico, desconsiderando em absoluto outras concepções subalternizadas, como foram e continuam sendo as indígenas. A relevância desta perspectiva teórica incide 
no fato de o estudo do colonialismo oferecer, conforme argumentam Irvine e Gal (2000), uma importante oportunidade para o estudo de ideologias linguísticas e dos choques de interesse em jogo na instituição de um saber hegemônico. Segundo as autoras,

ideias que foram forjadas neste contexto permaneceram profundamente incorporadas em nossos quadros analíticos. [...] [E]studiosos/as da linguagem e ideias sobre diferenças linguísticas desempenharam parte significante no desenvolvimento de categorias de identidade. Os argumentos sobre língua foram centrais na produção e no fortalecimento das reivindicações europeias pela diferença em relação ao resto do mundo, assim como da pretensão de superioridade da burguesia metropolitana sobre os Outros 'atrasados' e 'primitivos', tenham sido eles residentes em outros continentes, em outras províncias ou em outras classes sociais (IRVINE; GAL, 2000, p. 72-73).

Em conformidade com o enfoque central deste trabalho, faz-se necessário ainda um enquadre mais amplo no qual a linguagem possa ser abordada de forma mais específica e situada na construção da modernidade/colonialidade. Nesta direção, algumas proposições do chamado Paradigma da Desinvenção das Línguas podem servir de base para o desvelamento de estratégias através das quais a linguagem, bem como as (meta) reflexões sobre ela, tornaram-se instrumentos do poder colonial na América, de maneira geral, e no Brasil, especificamente, na instituição, na implementação e na continuidade da hierarquização de povos e de conhecimentos colonizados. Da mesma forma, apresenta importantes fundamentos para a descolonização de práticas, ideologias e regimes de linguagem dos quais a educação linguística intercultural pode se aproveitar.

A primeira premissa fundadora da ideia de desinvenção propõe que as “línguas, as concepções de linguacidade [languageness]e as metalinguagens usadas para descrevê-las são invenções” (MAKONI; PENNYCOOK, 2007, p. 01, destaques no original), premissa esta que implica outros aspectos, sendo o primeiro deles o fato de que as "línguas foram, em seu sentido mais literal, inventadas, particularmente, como parte dos projetos cristãos/coloniais e nacionalistas em diferentes partes do globo”. No que concerne à língua, argumentam os autores, “[o]s colonizadores europeus inventaram a si mesmos e os outros num processo recíproco. [...] Assim, não foram inventadas apenas as línguas colonizadas, mas também as línguas dos colonizadores” (MAKONI; PENNYCOOK, 2007, p. 8-9).

O interesse nos processos de invenção das línguas, conforme propõem Makoni e Pennycook, recai consequentemente sobre a nomeação destas como entidades discretas, pois conforme os autores, "o ponto de maior significância é que não se tratavam de novos nomes para objetos existentes (línguas pré-existentes à nomeação), mas da invenção e nomeação de novos objetos. A nomeação performativamente deu existência às 
línguas” (MAKONI; PENNYCOOK, 2007, p. 10). Nesta direção, conforme argumentam Makoni e Mashiri (2007, p. 70), "os rótulos não são meramente descritivos, eles são constitutivos”, o que fez com que os povos colonizados, mesmo na contemporaneidade, passassem a se enxergar através das lentes a eles atribuídas, o que pode ser descrito como um dos níveis de operação da colonialidade do poder (colonialidade do ser e do saber).

Makoni e Mashiri (2007, p. 67), destacam, ainda, a consequente discrepância resultante da nomeação de línguas por agências exógenas às comunidades de fala, como no caso da nomeação de "línguas indígenas", bem como seu legado contemporâneo, inclusive em áreas legitimadas dos estudos da linguagem, como a Linguística Aplicada. Segundo os autores,

[h]á também uma discrepância entre os nomes usados por linguistas e aqueles usados pelos próprios falantes. Os nomes usados por linguistas aplicados são normalmente as versões criadas pelos colonialistas [...]. Em termos etnometodológicos, os nomes das línguas usados pelos colonialistas e por linguistas aplicados não correspondem necessariamente àqueles usados pelos próprios falantes.

Nesta direção, os autores (MAKONI; MASHIRI, 2007, p. 67-68) destacam a necessidade de se prestar muita atenção a como os/as falantes constroem suas línguas e a necessidade de construírem-se descrições e classificações que considerem as perspectivas dos/as usuários/as, como parte do projeto de desinvenção e restituição das línguas, ou mesmo como um projeto de descolonização do pensamento e do conhecimento que têm formatado as chamadas 'línguas indígenas', através não só de sua nomeação, como de suas descrições.

Conforme Makoni e Pennycook (2007, p. 01), o projeto de desinvenção das 'línguas', ao argumentarem que tratam-se de construções socio-históricas, culturais e políticas situadas, busca ir além do ponto óbvio de que 'os critérios linguísticos não são suficientes para se estabelecer a existência de uma língua', sendo fundamental a identificação de importantes processos sociais e semióticos que levam a sua construção. Em Irvine e Gal (2000), por exemplo, as autoras problematizam os aspectos ideológicos subjacentes à diferenciação linguística, ou seja, à constituição de fronteiras ou de oposições entre repertórios de práticas comunicativas, considerando como ideologias 'as ideias com as quais participantes e observadores enquadram suas compreensões de variedades linguísticas e as mapeiam em povos, eventos e atividades que são significantes para eles’ (IRVINE; GAL, 2000, p. 35). Ao enfatizarem a dimensão ideológica deste mapeamento das práticas comunicativas, as autoras buscam destacar como estes esquemas ideológicos

estão impregnados de questões políticas e morais que permeiam o campo sociolinguístico particular e estão sujeitas aos interesses de seus condutores. 
As ideologias linguísticas são mantidas não apenas por participantes imediatos num sistema sociolinguístico local. Elas também são suportadas por outros observadores, como os linguistas e etnógrafos que mapearam as fronteiras entre línguas e povos e estabeleceram considerações descritivas sobre elas (IRVINE; GAL, 2000, p. 35-36).

Ao abordarem a construção da diferenciação linguística, as autoras buscam enfatizar, assim, que não existe 'visão de lugar nenhum’ na representação destas diferenças, pois são todas impregnadas por ideologias situadas e, mais importante ainda, 'atos de fala e atos de descrição são ambos dependentes de e contribuem com o 'trabalho de representação'. Estas representações por sua vez, influenciam no fenômeno que pretendem representar” (IRVINE; GAL, 2000, p. 79). Ou, como propõem Makoni e Meinhof (2006, p. 192-193), 'as descrições linguísticas constituem uma forma de intervenção social. Representações errôneas dessas realidades podem ter efeitos prejudiciais, mesmo se as descrições forem bem intencionadas', especialmente no campo aplicado das políticas e da educação linguísticas em contextos culturalmente complexos. No caso das 'línguas indígenas’ de territórios colonizados, Makoni e Pennycook (2007, p. 15) destacam que

[e]pistemologicamente, um dos principais movimentos retóricos do colonialismo foi nutrir, e mascarar, a artificialidade das línguas indígenas e das chamadas leis consuetudinárias, apresentando-as como se fossem partes naturais dos contextos locais [...]. Uma análise das formas como as línguas indígenas foram representadas reflete uma mudança na compreensão da língua de uma pautada na crença de que essas existem em e por si mesmas fora de relações de poder, para uma em que as línguas e suas descrições são vistas como 'impregnadas por relações de poder' [...]. Para que este foco em contextos coloniais e cristãos não sugira que nosso argumento situe-se apenas em épocas coloniais, o estendemos a eras pós-coloniais nas quais nos focamos no trabalho do Summer Institute of Linguistics (SIL) [...], que pode ser considerado 'como sucessor americano pós-colonial das missões da era colonial’ [...]. Para o SIL, há uma clara conexão entre linguística e cristandade.

Nesta direção, uma das principais dimensões da invenção das línguas em relação às línguas dos povos conquistados, e uma das grandes consequências, foi promover sua 'escritabilidade’ ou a conversão de formas orais em formas escritas, também como parte dos interesses coloniais e cristãos. Nesta direção, Souza (2007) argumenta, desde o contexto brasileiro, que políticas e práticas de usos da linguagem e do letramento direcionadas às populações indígenas através da educação, a diferença colonial e o conluio entre poder/conhecimento forjados no período colonial são amplamente mantidos na contemporaneidade. Conforme o autor, a "escrita, sua necessidade e suas formas de disseminação na educação indígena tendem a 
ser ancoradas em um lócus de enunciação não-indígena, que, entretanto, é inconsciente da localidade de seus próprios conceitos” (SOUZA, 2007, p. 139). Como consequência, ressalta o autor, há uma total negligência quanto à tradição oral indígena na pressuposição de que as concepções e os papéis da escrita em sociedades indígenas são idênticos aos papéis que desempenham na cultural ocidental.

De toda forma, como destacam Makoni e Pennycook (2007, p. 2324), a invenção das línguas tem consequências particularmente insidiosas para os povos indígenas, uma vez que a invenção do construto 'povos indígenas', principalmente em contextos multiculturais, produz para estes povos uma necessidade de identificação com identidades pré-nacionais, ou mesmo pré-coloniais, da qual a 'língua indígena' é parte fundamental. Esta construção da indianidade, contudo, tem um preço social, pois fixa e essencializa identidades, desqualificando povos indígenas urbanizados e aqueles que, por muitas razões, deixaram de usar as línguas originárias ou que se engajam em práticas comunicativas híbridas.

Nesta perspectiva, direcionando suas críticas e proposições ao campo da Linguística Aplicada contemporânea, os autores asseveram que qualquer projeto contemporâneo "por mais bem intencionado politicamente, deve incorporar formas de compreender os efeitos perniciosos que ele pode engendrar, a menos que confronte a necessidade da reconstituição da língua” (MAKONI; PENNYCOOK, 2007, p. 28). Esta proposição tem importantes consequências para o campo da formulação de políticas linguísticas em contextos multilíngues e interculturais, especialmente para o campo da educação linguística, pois pressupõe o questionamento das categorias dadas como pressupostas para a área, como o são, além da categoria 'língua’, suas correlatas, ‘língua materna’, 'língua herdada’, ‘bilinguismo’, 'bilinguismo aditivo', 'multilinguismo’ etc.

Para ilustrar as problematizações aqui propostas apresento, a seguir, algumas das situações que motivaram a reflexão mais aprofundada sobre disjunções concernentes às concepções de linguagem subjacentes a propostas interculturais de ensino situadas em zonas de contato.

\section{Diálogos interepistêmicos na zona de contato: problematizando concepções de "língua”, “língua materna” e "escrita”}

Como mencionado, as situações geradoras dos apontamentos críticos aqui apresentados emergiram-se nos trabalhos desenvolvidos no âmbito do curso de Educação Intercultural, em atividades sob minha supervisão ${ }^{3}$. Numa destas situações pedagógicas, ao ministrar o Tema Contextual: Português como primeira e segunda língua para professores e professoras indígenas concluintes do curso de Educação Intercultural, em 2011, foi proposto aos/às estudantes, através de uma atividade

\footnotetext{
${ }^{3}$ Durante as aulas do Tema Contextual: Português como primeira e segunda língua, em 2011, contei com a colaboração da então professora do curso Caroline Pereira de Oliveira.
} 
introdutória ao tema abordado, a análise e o confrontamento de categorias conceituais não-indígenas usadas na 'descrição' e na compreensão da realidade sociolinguística das comunidades indígenas brasileiras na contemporaneidade e que também são utilizadas no curso, especialmente no âmbito da Matriz Curricular Específica: Ciências da Linguagem ${ }^{4}$. O objetivo inicial desta atividade era simplesmente verificar como os professores e as professoras indígenas tinham, depois de cinco anos de curso, se apropriado de categorias 'descritivas' legitimadas no âmbito dos estudos da linguagem e amplamente repercutidas, para que, a partir daí, pudéssemos dar continuidade ao tema de estudo em questão.

Na discussão coletiva subsequente à resposta da atividade pelo/ as estudantes, pude perceber a heterogeneidade de suas reflexões e percepções quanto às categorias apresentadas, num nível tão profundo que, numa turma de aproximadamente 24 estudantes, praticamente nenhuma resposta coincidiu com a dos/as colegas. Cada resposta de cada estudante pautou-se numa perspectiva diferente para definir categorias como língua, língua materna, primeira língua, segunda língua, língua estrangeira, língua oficial, língua nacional, terceira língua, língua majoritária, língua minoritária, variedade linguística, bilinguismo, bidialetalismo etc. O mais relevante na ocasião foi, contudo, para além do objetivo da atividade proposta, a distinção apresentada pelos professores e professoras indígenas referente à significância das formas como normalmente suas 'línguas' são nomeadas pela tradição descritiva linguístico-antropológica não-indígena e que, normalmente, são apropriadas por eles e por elas, assim como por parte de suas comunidades na interação intercultural, mas que, num nível mais profundo, não são equivalentes às suas formas próprias de significarem, compreenderem e se referirem às suas práticas comunicativas.

Motivados, então, pelas reflexões dos/as professores/as indígenas, pedi para que os/as representantes de cada povo presente apresentassem para a turma as palavras ou expressões em suas línguas que se aproximassem da concepção de 'língua', como compreendida na tradição não-indígena, e construímos coletivamente o seguinte quadro, registrado em notas de aula, em julho de 2011:

\begin{tabular}{|c|c|}
\hline Povo & $\begin{array}{c}\text { Autonomeação das práticas originárias de linguagem } \\
\text { (tentativa de aproximação com a categoria ‘língua') }\end{array}$ \\
\hline Gavião (Pycopjê) & "Pyhcop Cati ji cacu” \\
\hline Karajá & "Iny rybè” \\
\hline Karajá Xambioá & "Iny rybè” \\
\hline Tapirapé & "Xe’ega apyãwa” \\
\hline Tapuia & "Português Tapuia” \\
\hline Xerente & "Akwẽ mremẽze” \\
\hline
\end{tabular}

\author{
${ }^{4}$ A partir do \\ terceiro ano do \\ curso de Educação \\ Intercultural da UFG, \\ os/as professores/as \\ indígenas optam por \\ uma das matrizes de \\ habilitação específica: \\ Ciências da Natureza, \\ Ciências da Cultura \\ ou Ciências da \\ Linguagem. Dada \\ a concepção \\ transdisciplinar do \\ curso, contudo, estas \\ matrizes mantêm \\ conexão constante.
}


A partir das explicações dadas por cada grupo, as traduções aproximadas das expressões seriam: "Pyhcop Cati ji cacu”, fala do povo Pyhcop Cati ji; "Iny rybè”, nossa fala ou a fala do povo Iny; "Xe'ega apyãwa”, fala do povo Apyãwa; “Akwẽ mremẽze”, fala do povo Akwẽ. No caso do "Português Tapuia", a explicação dada pelas estudantes presentes foi que a expressão buscava representar um diferencial em relação ao português brasileiro, dadas as especificidades socioculturais codificadas neste repertório linguístico-comunicativo próprio deste povo, constituindose, contudo, com o status e a legitimidade de uma língua, e não de uma "variedade linguística” com ilustra a reflexão abaixo5:

"Português Tapuia é uma língua porque é o conjunto de códigos usados na comunicação, serve para expressar a visão de mundo e o próprio mundo Tapuia, [é a] língua materna, pois é nossa identidade, assim como nós, ela é o resultado de um processo histórico e é formado como nós de grupos que se juntaram e se transformaram para se tornar um só.” (Eunice da R. Moraes Rodriguês)

A partir destas informações, fez-se notável a referência à dimensão oral da interação verbal (nossa fala, fala do povo) nas formas indígenas de concepção a respeito da linguagem, bem como um vínculo estreito com suas próprias culturas (fala do povo Iny, fala do povo Apyãwa etc.). Em nenhum momento da discussão houve qualquer vinculação entre linguagem e escrita. Além disso, pudemos perceber que as expressões usadas pelos professores e professoras indígenas, ao se referirem aos seus meios próprios de interação verbal, quando em tradução aproximada, não fazem qualquer menção à palavra ou à categoria "língua", no sentido como normalmente é elaborada e amplamente utilizada como pressuposta pelos estudos da linguagem produzidos pelo sistema-mundo ocidental.

Os/as estudantes indígenas informaram ainda que as referências à interação verbal próprias de cada cultura, representadas pelas expressões supracitadas, se aproximam muito mais da noção não-indígena de "linguagem" do que propriamente de "língua", palavra que referencia o órgão muscular situado na boca, para a qual existem outros termos particulares a cada cultura. Segundo os acadêmicos e acadêmicas indígenas, a tradução daquelas expressões indígenas por "língua” (i.e. categoria do campo da Linguística/Linguística Aplicada) que muitas vezes ocorre, deve-se à interlocução contingencial em contextos não-indígenas, como o de um curso universitário, por exemplo, na busca pela inteligibilidade intercultural. Em outras palavras, a tradução ocasional daquelas expressões por “língua karajá”, “língua tapirapé”, “língua gavião” etc., por parte dos/ as indígenas seria uma forma de adaptação ao contexto acadêmico nãoindígena, quando da interação com, por exemplo, professores e professoras não-indígenas.
${ }^{5}$ As informações de autoria dos/as professores indígenas aqui apresentadas foram retiradas de produções escritas geradas em atividades de sala de aula. Tanto sua publicação como a explicitação da autoria foram previamente autorizadas. Trata-se, ainda, de uma postura de reconhecimento de sua produção intelectual, o que me faz concebê-las não como dados a serem analisados, mas como instâncias de diálogo intercultural, portanto inter-epistêmico. 
Posteriormente, em agosto de 2012, tive a oportunidade de trabalhar o mesmo Tema Contextual com uma turma subsequente (ingressante em 2008) de professores/as indígenas e mais uma vez propus aquela atividade introdutória, considerando a presença de estudantes de povos diferentes daqueles do ano anterior. Nesta ocasião, antes mesmo de iniciarem as respostas individuais para a atividade, pedi para que os/as estudantes indígenas apresentassem oralmente palavras e expressões que, conforme sua compreensão, se relacionassem de alguma forma com a noção de 'língua', já que nosso tema de trabalho seria "Português como primeira e segunda língua”. Mais uma vez, as respostas e as correlações foram as mais diversas e significativas: 'conhecimento', 'pensamento', 'sabedoria', 'identidade', 'articulação da cultura', 'oralidade', 'costume', 'ritual', 'ferramenta', 'educação', 'sustentabilidade', 'movimento', 'comunicação', 'história', 'crenças', 'mitos', 'música', 'território'. A heterogeneidade das respostas sobre o que definiria língua não é exclusividade dos/as estudantes indígenas e muito menos uma novidade no campo dos estudos sobre a linguagem de tradição não-indígena.

O que, ao meu ver, merece destaque nas respostas dos/as professores/ as indígenas são os descritores utilizados para a categoria 'língua', muito diferentes daqueles que normalmente são postulados pelas diferentes 'correntes’ teóricas da Linguística e/ou da Linguística Aplicada hegemônicas, que apesar de heterogêneos, no caso das perspectivas indígenas, não pareceram 'incompatíveis entre si', mas complementares. Esta suposição pode ser preliminarmente elaborada quando percebi que nenhuma das contribuições foi questionada pelos/as demais estudantes durante a discussão, mas incentivadas e apoiadas coletivamente. Além disto, pelo que pude compreender na ocasião, os sentidos atribuídos pelos/as estudantes indígenas são estreitamente vinculados às suas práticas socioculturais e comunicativas locais, sem qualquer pretensão de abstracionismo universalmente válido ou totalitário. Não se trata, obviamente, de uma homogeneização forçada das percepções dos/as professores/as indígenas de povos e culturas diferentes sobre a linguagem, mas, ao contrário, de pistas para a constatação preliminar de que estes professores e professoras indígenas, por mais que estejam inseridos e em trânsito em espaços interculturais que legitimam e perpetuam o conhecimento de matriz anglo-eurocêntrica, como a universidade, concebem as manifestações da linguagem sob outras perspectivas.

Na sequência da atividade, foi proposta a mesma questão feita à turma anterior para a apresentação de expressões em suas 'línguas indígenas' que se aproximassem da categoria 'língua'. As respostas, em síntese, são apresentadas no quadro seguinte, produzido com base nas notas de sala de aula, em agosto de 2012: 


\begin{tabular}{|c|c|}
\hline Povo & $\begin{array}{c}\text { Autonomeação das práticas originárias de linguagem } \\
\text { (tentativa de aproximação com a categoria 'língua') }\end{array}$ \\
\hline Apinajé & "Mẽ pakapẽr” \\
\hline Javaé & "Iny Rybè” \\
\hline Karajá & "Iny rybè” \\
\hline Krahô & "Mẽ pa jarkwa” \\
\hline Tapirapé & “Apyãwa Xẽ'ega/ Apyãwa gy Xe’ega” \\
\hline Tapuia & "Português Tapuia” \\
\hline
\end{tabular}

As respectivas traduções aproximadas seriam "Mẽ pakapẽr”, 'fala nossa'; “Iny Rybè”, 'fala da gente’; “Iny rybè” 'fala do povo Iny’; “Mẽ pa jarkwa”, ‘fala do povo Krahô’; “Apyãwa Xẽ’ega/ Apyãwa gy Xe’ega”, 'fala Apyãwa'. Mais uma vez, para os/as estudantes Tapuia, a questão que se impôs referiu-se ao controverso status do "Português Tapuia” como língua ou como variedade do português brasileiro.

Mais uma vez, em julho de 2013, a mesma atividade foi desenvolvida com as turmas ingressantes em 2009 e 2011. As informações e reflexões oriundas da atividade realizada com estas turmas aproximaram-se das concepções apresentadas pelos/as colegas das turmas anteriores, especialmente no que se refere à parcialidade e a localização de suas concepções de linguagem. Nesta última ocasião, contudo, pode-se perceber, numa das respostas, um vínculo mais nítido com uma das dimensões da visão de mundo indígena que, diferentemente do pensamento racional moderno/ colonial, não dicotomiza a interação entre res cogitam e res extensa, entre o humano e o não humano, entre a mente e o espírito, entre o sensível e o inteligível (HART, 2010, p. 8), como se percebe no seguinte trecho:

“O nosso meio de comunicação como povo Apyãwa denomina-se Xe'ega. Xe’ega significa para denominar: fala, conversa e fofoca. Mas o contexto de Xe'ega não significa apenas isso, vai além, ou seja, arte, histórias, mitos cantos, rituais, são parte do contexto de Xe'ega (língua). O termo Xe’ega também não significa apenas para denominar nossa forma de comunicação como um povo. Inclusive usamos esse termo para denominar as cantorias ou falas de outros seres da natureza, os animais, aves peixes etc. Assim nós como povo Apyãwa usamos esse termo Xe'ega.” (Klebson Awararawoo’i Tapirapé)

Outra situação significativa foi vivenciada no trabalho específico com os povos Xambioá e Guarani Mbyà na Terra Indígena Xambioá. Como base para as atividades de Estágio Pedagógico do curso de Educação Intercultural e para a reflexão em torno da elaboração da Proposta Político-Pedagógica das escolas da região, os/as professores/as indígenas realizaram um levantamento sociolinguístico visando, principalmente, a 
informações sobre os repertórios linguísticos mais usados nas comunidades e também a atitudes linguísticas de seus/as membros quanto às práticas comunicativas em línguas indígenas e em português. Entre a população da região, as práticas comunicativas mais difundidas ocorrem em língua portuguesa, principalmente entre a população Xambioá, o que fez com que estas práticas se tornassem as primeiras adquiridas pelas gerações mais jovens, ao passo que as práticas comunicativas em 'língua indígena’ passassem a ser usadas apenas por anciãos e anciãs.

Contudo, mesmo diante deste quadro, as práticas comunicativas na língua indígena continuam sendo uma forte referência identitária para toda a população Xambioá. Esta constatação ficou evidente através das respostas ao questionário sociolinguístico mencionado, no qual às perguntas sobre as primeira e segunda línguas adquiridas foi comum a resposta "primeira língua: portuguesa. Segunda língua: a língua materna.” Estas informações fornecem, em minha interpretação, importantes evidências acerca das formas de concepções indígenas, ou ao menos de suas formas de apropriação e ressignificação, do que venha a designar a categoria 'língua materna'. A partir das respostas no referido levantamento sociolinguístico, percebe-se o forte caráter identitário atribuído ao conceito, independentemente se se refere à língua mais usada socialmente ou mesmo à primeira adquirida.

Este forte sentido étnico-identitário atribuído à noção de "língua materna” é confirmado nas reflexões dos/as professores/as indígenas, com pode ser visto nos fragmentos a seguir:

“É uma linguagem que o indivíduo nasce com ela no sangue, no coração, ou seja, a língua mãe ou a linguagem original do indivíduo.” (Valci Sinã)

“A língua materna é a língua que falamos no dia a dia. Essa língua é falada pelos nossos pais e pelo nosso povo. Nascemos e aprendemos falar primeiro a língua materna.” (Leandro Lariwana Karajá)

“É a língua da mãe, língua própria de um povo, por exemplo, a língua materna do povo Tapirapé é a língua Tapirapé.” (Gilson Ipara’awyga Tapirapé)

"É a língua que é própria de seu povo, que o representa historicamente e culturalmente.” (Eunice da Rocha Moraes Rodriguês)

"É a língua de cada povo para comunicar e se expressar. Cada língua tem sua estrutura gramatical própria.” (Jonas Polino Sansão)

"A língua materna que marca identidade, cultura, costume e convivência. Então, o que é de tradição, de origem do povo, não podemos perder, porque sem ela não somos ninguém, portanto é importante cuidar dela." (Wasari Karajá) 
Este forte vínculo identitário entre ‘língua’ e ‘povo’ que é atribuído à e se projeta fortemente na noção de 'língua materna’ pode acarretar, ao meu ver, situações conflitivas, por outro lado. Numa outra situação, quando os professores e professoras indígenas Xambioá apresentavam seus trabalhos num seminário para todos/as estudantes do curso de Educação Intercultural, em janeiro de 2012, um professor Xambioá foi interpelado por uma professora indígena 'bilíngue', proveniente de outro povo, sobre 'como se sentia sendo um professor bilíngue que não fala a língua materna'. À pergunta seguiu-se a resposta: "Me sinto muito constrangido, muito envergonhado por não falar minha língua materna”.

Neste contexto, é interessante observar a reprodução do que Hutton (2010, p. 645) chama de paradoxo do modelo de identidade linguística língua materna - falante nativo. O autor destaca que, como uma das consequências da experiência moderna/colonial, a apropriação deste modelo identitário pelos povos indígenas para a defesa da diferença requer o uso de categorias fundadas, por sua vez, em ideologias do discurso identitário eurocentrado, que vincula um povo - um território - uma língua, e tem seu ápice no Romantismo alemão e na filologia do século XIX e, como destacado, é parte integrante das estratégias de invenção das línguas para controle e dominação (MAKONI; PENNYCOOK, 2007, p. 23-24).

Para situações como estas, torna-se fundamental compreender que a imputação de concepções de língua, língua materna, bilinguismo etc. fundadas e construídas tendo falantes ou comunidades indígenas bilíngues idealizadas como parâmetros pode se tornar mais uma fonte/forma de opressão contra povos que vivenciaram mudanças socioculturais drásticas devido às relações violentas com as sociedades não-indígenas, desde a colonização e como consequência dela, impelindo-os ao uso predominante de práticas comunicativas nas línguas hegemônicas. Em outras palavras, trata-se de um ato talvez mais violento e certamente covarde atribuir às vítimas (num sentido histórico) o papel de culpadas, ou pelo menos o de responsáveis pela situação sociolinguística contemporânea de seus povos, de suas comunidades ou de suas escolas. Neste sentido, mesmo propostas que visam à emancipação, como a chamada 'educação bilíngue intercultural', teriam efeitos contrários se não se considerarem os contextos locais de sua implementação e se não houver uma revisão crítica de pressupostos subjacentes e inquestionados, como os são "língua”, “bilinguismo” e "língua materna”, dentre outros, e se se partir de relações inequívocas, fixas, idealizadas ou romantizadas entre língua, cultura e identidade indígenas, num mundo transformado pelo colonialismo e pela globalização geocultural.

Makoni e Pennycook (2007, p. 30) advertem, no entanto, que as orientações conceptuais adotadas no projeto de desinvenção e reconstituição das línguas devem se afastar do totalitarismo da experiência racional moderna/colonial e variar a depender dos problemas que se colocam, para 
os quais o mais adequado não seria pensar em soluções, mas em 'alternativas viáveis', por sua vez, uma opção mais realista. Assim,’em algumas situações a solução viável pode estar na essencialização das línguas maternas, em outros casos, em sua problematização”. Em outras palavras, para compor epistemologias sobre linguagem em zonas de contato, a ideia de língua materna, se é que ainda relevante, deve ser desinvestida de seu status idilicamente fetichizado e totalitário e passar por profunda revisão em direção à relacionalidade e à contingência contextual. Só assim, pode ser considerada uma ideia útil para o que Spivak (1987, p. 206-207 apud HUTTON, 2010, p. 645) chama de “essencialismo estratégico” e não assumida acriticamente como critério de inferiorização entre os próprios povos indígenas.

Uma outra situação bastante ilustrativa da forma como concepções indígenas e não-indígenas concernentes à linguagem, mais especificamente sobre concepções de escrita e escolarização, se confrontam, são apropriadas e ressignificadas, é apresentada por Júlio Kamêr, professor do povo Apinajé, originada durante o trabalho no Tema Contextual: Linguagem escrita e suas funções sociais, ministrado também por mim no âmbito da Matriz Específica: Ciências da Linguagem, em agosto de 2011. Em sua interpretação, o professor Apinajé explicou que, assim como para muitos povos indígenas brasileiros, a apropriação de práticas escritas é um fenômeno bastante recente, contexto no qual as 'línguas indígenas' tiveram de buscar formas de apropriação e significação a fim de refletirem as concepções a elas concernentes. Para o povo Apinajé tais processos seguiram a seguinte trajetória:

- Palavras que se referiam ao grafismo particular do povo Apinajé, como hak (pintura) e kagà (risco) foram ressignificadas para se aproximarem da noção de escrita não-indígena em expressões como kagà hôk (escrita), esta usada pelas pessoas mais velhas de seu povo;

- Mais recentemente, outras expressões surgiram e passaram a ser mais usadas na atualidade para representar a escrita ou o ato de escrever, tais como kagà nhẽpê (literalmente, fazer escrita, ou escrever/escrita), assim como aos novos instrumentos usados nesta atividade, como kagà hôk xà (caneta/lápis);

- Também com origem na tradição dos grafismos Apinajé, passaram a fazer parte do repertório linguístico deste povo palavras e expressões que designam a escola, kagà jahkre xà (local onde se ensina a escrita/ escola), bem como professor/a, kagà jahkre xwỳnh (aquele que ensina a escrita/professor).

- $\quad$ O kagà jahkre xwỳnh Apinajé, na ocasião, ressaltou que a concepção de escola vinculada à escrita, kagà jahkre xà, não podia se confundir com outros espaços-tempos de educação indígena, cujo local é mais bem concebido em sua 'língua' através da expressão mẽ ah krexà (local de educar). 
Esta situação se torna significativa para as problematizações aqui abordadas na medida em que remete a possibilidades de compreensão que podem, por um lado, demonstrar as vias de interpretação de situações geradas no encontro com o não-indígena e da apropriação indígena de seus artefatos culturais, como a escrita alfabética de base latina e seus produtos e, como consequência, mesmo que indiciariamente, revelar outros processos e estratégias a elas vinculadas, sejam eles de opressão, violência epistêmica, assimilação, ou mesmo de ressignificação, apropriação e resistência, uma vez que, conforme destaca Sahlins (1997 apud ALBERT, 2002, p. 13), “a continuidade das culturas indígenas consiste nos modos específicos pelos quais elas se transformam.” Por outro lado, tais transformações podem fornecer vias interpretativas para o questionamento de uma visão etno(euro)grafocêntrica que, desde o início da colonização europeia, usou o recurso da 'escrita', ou sua posse, como critério de classificação dos povos conquistados (normalmente em posições inferiores) de outros territórios, segundo o argumento de que 'povos sem escrita são povos sem história e mesmo incapazes de por si só escrevê-la’ (MIGNOLO, 1998, 2000). Através da breve apresentação acima, com base na explicação do kagà jahkre xwỳnh Apinajé, por exemplo, poder-se-ia, mesmo que preliminarmente, supor que, a materialidade gráfica de seu povo, antes do encontro com o não-indígena ou mesmo na contemporaneidade, desempenha/va funções que se aproximam da concepção mais recente do que seria a 'escrita do não-indígena', como por exemplo, 'a escrita sem palavras' (BOONE; MIGNOLO, 1994) de sua cosmologia, de sua organização sociocultural, de sua 'história' etc. (CALVET, 2011). Esta suposição é endossada pela proximidade entre termos que vinculam palavras que originalmente se relacionam com o grafismo e a pintura indígenas e as palavras relacionadas à escrita e seus produtos, como ilustram os exemplos a seguir informados durante o trabalho no Tema Contextual: Linguagem escrita e suas funções sociais, ministrado também por mim no âmbito da Matriz Específica: Ciências da Linguagem, em março de 2013:

i) Akwẽ mremẽze (língua Xerente) ${ }^{6}$ :

Kakuĩkre: desenho/grafismo

kuĩkreze: escrita

${ }^{6}$ Informação dada pela professora Sílvia Letícia Xerente.

ii) Iny Rybè (língua Karajá) 7 :

Rirtiny: desenho

Rti: grafismo/pintura

Rti: escrita

Tyyrtina heto: escola (lugar do papel)

Esta relação faz parte, ainda, da representação de escrita elaborada por alguns professores, como ilustram os seguintes trechos de suas reflexões, geradas no contexto do Tema Contextual: Linguagem escrita e suas funções sociais, ministrado janeiro de 2011: 
"O grafismo - os traços que são feitos nos corpos dos iny, tem significados, cada traço tem a função definida e de acordo com essa definição recebe o nome. Cada traço da pintura tem o seu tamanho e contornos certos, funciona como alfabeto. Se uma perna ou traço não ligar com o outro, quem conhece, não fará leitura, ou seja, discrimina.” (Sinvaldo de Oliveira)

"acredito que provavelmente estávamos no rumo da escrita ou melhor estava surgindo uma forma de escrita, que é conhecido como grafismo, hoje é conhecido como pintura corporal. Por que cada pintura representa alguma coisa, provavelmente objetivo não era escrever mas é o caminho, e aqui coloco alguns exemplo: Hãru = espécie de pacu - peixe; Hojuju = ganchu; Aóti $=$ espinho de peixe [...] Esses são alguns exemplos e existe mais, por isso que eu acredito que estavamos no início do nascimento da escrita." (Leandro Lariwana Karajá)

Um possível impacto desta compreensão para as concepções de escrita nas zonas de contato seria, a título de exemplo, a potencialização da multimodalidade textual, que possibilitaria, por sua vez, novos caminhos para formas mais ricas de produção e socialização do conhecimento, uma vez que incorpora como constitutivas também a diversidade de práticas de conhecimento materializadas na oralidade e em linguagens não-verbais.

\section{Considerações finais e perspectivas}

As situações pontuais e localizadas aqui apresentadas se, por um lado, não apresentam de maneira conclusiva concepções e/ou apropriações indígenas concernentes à linguagem, por outro lado, as evidências delas originadas suscitam problemas muito maiores e mais profundos, que dizem respeito às próprias bases epistemológicas e ontológicas com as quais a Linguística e seu entorno têm se assentado mesmo ao se proporem analisar e atuar em contextos sociolinguisticamente complexos, como os são os territórios pluriculturais e plurilíngues pós-coloniais contemporâneos, cujos povos vivenciaram processos de colonização e, de maior importância ainda, quando propõem o diálogo epistemológico intercultural como base para transformações nas políticas e práticas educativas escolares dos povos indígenas.

Dentre esses problemas destacam-se aqui a construção e a legitimação de categorias ‘descritivo-analíticas', que alegadamente referenciam realidades pré-existentes e que se tornaram pressupostas, sendo portanto inquestionadas, e seu amplo, difundido e perpetuado uso, mesmo em contextos que propõem o “diálogo intercultural”, como o é o do curso de Educação Intercultural e de muitas outras instituições e programas de educação intercultural direcionados a povos indígenas brasileiros. Considerando-se as bases e concepções da educação intercultural transdisciplinar, principalmente quando adotadas por cursos de formação 
de professores/as indígenas, como apresentadas anteriormente, torna-se fundamental o questionamento sobre se e como as concepções indígenas a respeito da linguagem têm feito parte das reflexões e da construção das epistemologias da área. O que de fato definem, abarcam e excluem as expressões apresentadas pelos/as acadêmicos/as, ao meu ver, continua sendo não implementado ou mesmo desconhecido pela academia, enfatizo, mesmo quando esta se propõe intercultural.

Nesta direção, fundamento meu argumento na necessidade do reconhecimento de lógicas e perspectivas outras concernentes às concepções de linguagem a partir das quais se possa, de fato, estabelecer e implementar abordagens analíticas mais coerentes com a realidade intercultural pós-colonial que se emerge a partir das interações entre indígenas e não-indígenas na contemporaneidade, especialmente quando os povos indígenas conquistam cada vez mais espaços nas universidades brasileiras, colocando em cheque as bases analíticas a partir das quais sempre foram estudados, analisados e classificados, assim como as diferentes dimensões de suas vidas, desde o ponto de vista não-indígena. O reconhecimento e a implementação destas lógicas outras podem, em minha interpretação, contribuir com a construção de paradigmas mais adequados para a formação de professores/ as indígenas e com a própria educação escolar indígena, mas, principalmente, com transformação da universalidade monotópica da tradição acadêmica de matriz eurocentrada em uma pluriversidade fundada em outras genealogias não totalizantes de conhecimento (MIGNOLO, 2010).

\section{Referências}

ALBERT, B. Introdução: Cosmologias do contato no Norte-Amazônico. In: ALBERT, B.; RAMOS, A. R. (Org.). Pacificando o branco: Cosmologias do contato no Norte-Amazônico. São Paulo: Editora Unesp/ Imprensa Oficial do Estado, 2002. p. 9-21.

BOONE, E. H.; MIGNOLO, W. D. (eds.). Writing without words: Alternative literacies in Mesoamerica \& the Andes. Durhan/London: Duke University Press, 1994.

CALVET, L-J. Tradição oral e tradição escrita. Tradução de Waldemar Ferreira Netto e Maressa de Freitas Vieira. São Paulo: Parábola, 2011.

HART, M. A. Indigenous worldviews, knowledge, and research: the development of an indigenous research paradigm. Journal of indigenous voices in social work, v. 1, n. 1, fev., 2010, p. 1-16. Disponível em: http://scholarspace.manoa.hawaii.edu/bitstream/handle/10125/15117/ v1i1_04hart.pdf?sequence=1. Acesso em: abr. 2014.

HUTTON, C. Who owns language? Mother tonges as intellectual property and the conceptualization of human linguistic diversity. Language Sciences, 32, p. 638-647. 2010. 
IRVINE, J.; GAL, S. Language ideology and linguistic differentiation. In: KROSKRITY, P. V. (ed.). Regimes of language: Ideologies, Politics and Identities. Santa Fe, NM: School of American Research Press, 2000. p. 35-85.

LANDER, E. Ciencias sociales: saberes coloniales e eurocéntricos. In: LANDER, E. (comp.). La colonialidad del saber: eurocentrismo e ciencias sociales - Perspectivas latino americanas. Buenos Aires: CLACSO, 2000. p. 9-38.

MAKONI, S.; MASHIRI, P. Critical historiography: Does language planning in Africa needs a construct of language as part of its theoretical apparatus? In: MAKONI, S.; PENNYCOOK, A. (eds.). Disinventing and reconstituting languages. Clevedon/Buffalo/Toronto: Multilingual Matters, 2007. p. 62-89.

MAKONI, S.; MEINHOF, U. Linguística aplicada na África: desconstruindo a noção de "língua”. Tradução de Luiz Paulo da Moita Lopes. In: MOITA LOPES, L. P. (Org.). Por uma linguística aplicada indisciplinar. São Paulo: Parábola, 2006. p. 191-213.

MAKONI, S.; PENNYCOOK, A. Disinventing and reconstituting languages. In: MAKONI, S.; PENNYCOOK, A. (eds.). Disinventing and reconstituting languages. Clevedon/Buffalo/Toronto: Multilingual Matters, 2007. p. 1-41.

MALDONADO-TORRES, Nelson. Sobre la colonialidad del ser: contribuciones al desarrollo de un concepto. In: CASTRO-GÓMEZ, S.; GROSFOGUEL, R. (Org.) El giro decolonial. Reflexiones para una diversidad epistémica más allá del capitalismo global. Bogotá: Universidad Javeriana-Instituto Pensar, Universidad Central-IESCO, Siglo del Hombre Editores, 2007. p. 127-167.

MIGNOLO, W. D. The darker side of the Renaissance: literacy, territoriality, and colonization. $4^{\text {th }}$ ed. Michigan: University of Michigan Press, 1998.

MIGNOLO, W. D. Local/histories/Global designs: coloniality, subaltern knowledges, and border thinking. Princeton: Princeton University Press, 2000 .

MIGNOLO, W. D. Desobediencia epistémica: retórica de la modernidad, lógica de la colonialidad y gramática de la descolonialidad. Buenos Aires: Ediciones del signo, 2010.

MIGNOLO, W. D. The darker side of Western Modernity: global futures, decolonial options. Durham/London: Duke University Press, 2011. 
PRATT, M. L. Arts of contact zone. Profession, 1991. p. 33-40.

QUIJANO, A. Colonialidad y modernidad-racionalidad. In: BONILLA, H. (comp.). Los conquistados: 1492 y la población indígena de las Américas. Bogotá: Tercer Mundo/Flacso, 1992. p. 437-447.

QUIJANO, A. Colonialidad del poder, eurocentrismo y América Latina. In: LANDER, E. (comp.). La colonialidad del saber: eurocentrismo y ciencias sociales - Perspectivas latinoamericanas. Buenos Aires: CLACSO, 2000. p. 193-238.

SOUZA, L. M. M. Entering a culture quietly: writing and cultural survival in Indigenous education in Brazil. In: MAKONI, S.; PENNYCOOK, A. (ed.). Disinventing and reconstituting languages. Clevedon/Buffalo/ Toronto: Multilingual Matters, 2007. p. 135-169.

WALSH, C. Interculturalidade crítica e pedagogia decolonial: in-surgir, reexistir e re-viver. In: CANDAU, V. M. (org.). Educação intercultural na América Latina: entre concepções, tensões e propostas. Rio de Janeiro: 7 Letras, 2009. p. 12-42.

Data de submissão: 17/04/2014

Data de aprovação: 21/08/2014 